\title{
Robotic versus laparoscopic gastrectomy with D2 lymph node dissection for advanced gastric cancer: a propensity score-matched analysis
}

This article was published in the following Dove Press journal: Cancer Management and Research

\author{
Zhengyan Li \\ Jipeng Li \\ Bofei Li \\ Bin Bai \\ Yezhou Liu \\ Bo Lian \\ Qingchuan Zhao
}

Department of Surgery, Xijing Hospital of Digestive Diseases, The Fourth Military Medical University, Xi'an, China
Correspondence: Qingchuan Zhao

Xijing Hospital of Digestive Diseases, The

Fourth Military Medical University, 127

Changle West Road, Xi'an 710032, China

Tel +86 298477 I503

Fax +86 298477 I503

Email zhaoqc62@yahoo.com
Background: Robotic gastrectomy $(\mathrm{RG})$ is a new surgical method alternative for gastric cancer. However, few studies have evaluated the outcomes of RG for advanced gastric cancer (AGC). Thus, the aim of this study was to compare the short-and long-term outcomes of RG and laparoscopic gastrectomy (LG) with D2 lymph node dissection for AGC.

Patients and methods: We retrospectively evaluated 454 patients with AGC who underwent RG or LG with D2 lymph node dissection for AGC between August 2013 and March 2017. The short-and long-term outcomes were compared between the propensity score-matched groups. Results: The RG group was associated with longer operation time, less intraoperative blood loss, and higher hospital cost. Additionally, there was a tendency favoring RG in terms of number of harvested lymph nodes, time to first flatus, time to first start diet, and postoperative hospital stay, although the differences were not statistically significant. The overall postoperative complication rate was $13.4 \%$ and $11.6 \%$ in the RG and LG groups, respectively, with no significant difference $(P=0.686)$. The 3-year overall survival and recurrence rates of the RG and $\mathrm{LG}$ groups were also comparable ( $78.6 \%$ vs $74.1 \%, P=0.483 ; 18.8 \%$ vs $21.4 \%, P=0.617$; respectively).

Conclusion: RG with D2 lymph node dissection is safe and feasible for AGC in terms of both short- and long-term outcomes. High-volume randomized controlled trials with sufficient follow-up are needed to confirm this rationale.

Keywords: robotic gastrectomy, laparoscopic gastrectomy, advanced gastric cancer

\section{Introduction}

Gastric cancer is a worldwide health concern and is the second leading cause of cancer-related deaths in China. ${ }^{1}$ Gastrectomy with proper perigastric lymph node dissection remains the cornerstone of radical resection of potentially curable gastric cancer. With the advantages of minimally invasive and better short-term outcomes, laparo-scopic gastrectomy (LG) for gastric cancer has garnered tremendous popularity over open gastrectomy. ${ }^{2,3}$ Currently, extensive researches have reported that laparoscopy-assisted gastrectomy (LAG) is a safe and feasible procedure with better short-term outcomes and equivalent long-term survival outcomes compared with open gastrectomy (OG). ${ }^{4-6}$ Robotic surgery has been introduced as a better operation method with several advantages, which could overcome the technical limitations of conventional laparoscopy. There is evidence that the robotic gastrectomy (RG) could help to overcome some technical difficulties encountered when performing laparoscopic surgery, such as lymph node dissection, handling deep-seated vessels, and intracorporeal anastomoses..$^{7-10}$ However, these studies mainly focused on early 
gastric cancer, and majority of them only evaluated shortterm outcomes. There is still a lack of well-matched studies that report long-term outcomes of RG with D2 lymph node dissection for patients with advanced gastric cancer (AGC). We, therefore, designed this study to compare the short-and long-term outcomes of RG and LG for AGC using a propensity score-matching analysis.

\section{Patients and methods}

\section{Patients}

Patients with postoperative pathological diagnoses of AGC who underwent RG or LG were screened from the prospectively maintained gastric cancer database at the Department of Digestive Surgery, Xijing Hospital of Digestive Diseases, Fourth Military Medical University from August 2013 to March 2017. The inclusion criteria were as follows: 1) histologically confirmed adenocarcinoma by gastroscopy and pathological biopsy; 2) depth of invasion confined to pT2, pT3, or pT4a; 3) no distant metastasis or invasion to adjacent organs; 4) not combined with other malignancy; 5) no emergency operation; and 6) no preoperative chemotherapy or radiation therapy was performed. Ultimately, 454 patients were included in the analysis. The entire cohort included 125 and 329 patients who underwent RG and LG, respectively. To reduce the effect of potential confounding due to the limits of respective studies, we performed propensity score matching using a logistic regression model with the following variables: age, gender, comorbidities, tumor size, extent of resection, histologic type, $\mathrm{pT}$ stage, $\mathrm{pN}$ stage, and pTNM stage. We performed one-to-one matching using a 0.02 caliper width. Finally, the propensity score-matched cohort comprised 112 cases in each group. Pathologic staging was evaluated according to the 8th Union for International Cancer Control/American Joint Committee on Cancer staging system of gastric cancer. ${ }^{11}$ Postoperative complications were recorded and classified according to the Clavien-Dindo classification system. ${ }^{12,13}$

\section{Surgical procedure}

The patients chose the surgical procedure (RG vs LG) by their individual decision after they were informed of the advantages and risks of each procedure. Patients in the 2 groups underwent distal gastrectomy (DG) or total gastrectomy (TG) based on the location of tumor. D2 lymph node dissection was performed according to the Japanese Gastric Cancer Treatment Guidelines (version 3). ${ }^{14}$ During TG, spleen-preserving No. 10 lymph node dissection and omentectomy were performed. The reconstruction type (gastroduodenostomy or gastrojejunostomy for DG and Roux-en-Y esophagojejunostomy for TG) was selected according to the surgeon's preference. The extracorporeal reconstructions were mostly conducted in our center. We routinely administered postoperative adjuvant chemotherapy with 5-fluorouracil and cisplatin. This study was approved by the ethics committee of Xijing Hospital, and written informed consent was granted by the patients.

\section{Postoperative evaluation and follow-up}

Postoperative complications were recorded as complications that occurred within 30 days after surgery. Patients were followed up every 3 months during the first 2 years and then every 6 months from 2 to 5 years. The length of follow-up was defined as the time from surgery to the final follow-up date of December 2017 or time of death. Cancer recurrence was diagnosed based on radiologic or histological signs of disease.

\section{Statistical analysis}

The data were analyzed using SPSS, version 22.0 (SPSS Inc., Chicago, IL, USA). All continuous variables are presented as the mean $\pm \mathrm{SD}$. The chi-square test was used to compare categorical variables between the 2 groups, and the independent sample $t$-test or Mann-Whitney $U$-test was used to compare continuous variables. Overall survival (OS) curves were calculated using the Kaplan-Meier method and analyzed by the log-rank test. $P$-values $<0.05$ were considered statistically significant.

\section{Results \\ Clinicopathologic characteristics}

The clinicopathological characteristics of the patients are summarized in Table 1. The background characteristics were well matched, with no significant differences in gender, age, body mass index (BMI), tumor size, extent of resection, histological type, $\mathrm{pT}$ stage, $\mathrm{pN}$ stage, pTNM stage, and comorbidities between the RG and LG groups.

\section{Surgical outcomes and postoperative complications}

The surgical outcomes and postoperative complications are summarized in Table 2. The intraoperative blood loss was significantly reduced in the RG group compared with the LG group (179.2 vs $234.9 \mathrm{~mL}, P=0.000)$. However, the operative time was significantly longer in the RG group than that in the LG group (261.7 vs $227.8 \mathrm{~min}, P=0.000$ ). Additionally, the total cost of hospitalization was significantly higher in the RG group than that in the LG group (92365.0 vs 69476.5 
Table I Characteristics of patients

\begin{tabular}{|c|c|c|c|c|c|c|}
\hline \multirow[t]{2}{*}{ Variables } & \multicolumn{2}{|c|}{ Entire cohort } & \multirow[t]{2}{*}{$P$-value } & \multicolumn{2}{|c|}{ Propensity score-matched cohort } & \multirow[t]{2}{*}{$P$-value } \\
\hline & RG (n=125) & LG $(n=329)$ & & RG (n=II2) & LG (n=II2) & \\
\hline Age (years) & $55.4 \pm 11.5$ & $56.9 \pm 10.5$ & 0.197 & $55.6 \pm 11.3$ & $56.1 \pm 11.1$ & 0.725 \\
\hline Gender (male/female) & $84 / 41$ & $229 / 100$ & 0.621 & $78 / 34$ & $79 / 33$ & 0.884 \\
\hline Body mass index $\left(\mathrm{kg} / \mathrm{m}^{2}\right)$ & $23.7 \pm 2.8$ & $23.1 \pm 3.0$ & $0.04 I$ & $23.6 \pm 2.9$ & $23.6 \pm 3.0$ & 0.856 \\
\hline Tumor size $(\leq 5.0 />5.0 \mathrm{~cm})$ & $91 / 34$ & $239 / 90$ & 0.973 & $83 / 29$ & $84 / 28$ & 0.878 \\
\hline Comorbidities (present/absent) & $25 / 100$ & $85 / 244$ & 0.195 & $23 / 89$ & $24 / 88$ & 0.870 \\
\hline Histological type & & & 0.000 & & & 0.494 \\
\hline Well/moderately & 28 & 133 & & 23 & 19 & \\
\hline Poorly/undifferentiated & 97 & 196 & & 89 & 93 & \\
\hline pT stage & & & 0.006 & & & 0.960 \\
\hline $\mathrm{T} 2$ & 47 & 82 & & 38 & 36 & \\
\hline T3 & 45 & 113 & & 41 & 42 & \\
\hline $\mathrm{T} 4 \mathrm{a}$ & 33 & 134 & & 33 & 34 & \\
\hline $\mathrm{pN}$ stage & & & 0.048 & & & 0.821 \\
\hline No & 41 & 97 & & 36 & 35 & \\
\hline $\mathrm{NI}$ & 42 & 86 & & 36 & 35 & \\
\hline N2 & 25 & 66 & & 25 & 27 & \\
\hline N3a & 13 & 41 & & 12 & 9 & \\
\hline N3b & 4 & 39 & & 3 & 6 & \\
\hline pTNM stage & & & 0.031 & & & 0.993 \\
\hline IB & 24 & 37 & & 20 & 18 & \\
\hline$\| \mathrm{A}$ & 27 & 55 & & 22 & 23 & \\
\hline IIB & 24 & 72 & & 22 & 21 & \\
\hline IIIA & 26 & 64 & & 25 & 25 & \\
\hline IIIB & 17 & 53 & & 16 & 19 & \\
\hline IIIC & 7 & 48 & & 7 & 6 & \\
\hline
\end{tabular}

Note: Data are presented as mean \pm standard deviation.

Abbreviations: LG, laparoscopic gastrectomy; RG, robotic gastrectomy.

$\mathrm{RMB}, P=0.000)$. No significant difference was found between the 2 groups in terms of number of harvested lymph nodes (29.5 \pm 9.6 vs $27.8 \pm 8.7, P=0.149)$, time to first flatus $(2.6 \pm 0.6$ vs $2.8 \pm 1.1, P=0.124)$, time to start liquid $\operatorname{diet}(1.6 \pm 0.7$ vs $1.7 \pm 0.5, P=0.320$ ), time to start soft diet ( $3.6 \pm 1.6$ vs $3.9 \pm 2.0$, $P=0.179)$, and days of postoperative hospital stay $(6.9 \pm 2.3$ vs $7.0 \pm 3.8, P=0.718$ ).

There was no intraoperative or 30-day postoperative mortality. The incidences of overall complications did not differ significantly between the RG and LG groups (13.4\% vs $11.6 \%, P=0.686$ ). Moreover, no significant differences were noted in the minor (Clavien-Dindo grade II) and major complication (Clavien-Dindo grade $\geq \mathrm{IIIa}$ ) rates between the 2 groups $(6.3 \%$ vs $5.4 \%, P=0.775 ; 7.1 \%$ vs $6.3 \%, P=0.789$; respectively). Regarding individual complications, the incidence of wound problem, anastomotic leakage, duodenal stump fistula, and abdominal infection were also similar between the 2 groups.

\section{Surgical outcomes and postoperative complications in different phases}

To examine the learning curve effect, we performed subgroup analysis by dividing the patients into 2 phases. The initial and late phase both comprised 56 patients in each group. Table 3 shows surgical outcomes and postoperative complications in different phase between the 2 groups. The operative time was significantly longer in the RG group than those in the LG group during the initial phase (286.0 vs $236.8 \mathrm{~min}$, $P=0.000)$. In the late phase, no significant differences were noted between the two groups ( 237.4 vs $218.8 \mathrm{~min}, P=0.060$ ). The number of harvested lymph nodes, time to first flatus, time to start liquid diet, time to start soft diet, days of postoperative hospital stay, and incidence of overall postoperative complications were not significantly different between the RG and LG groups in the initial or late phase $(P>0.05)$.

\section{Subgroup analysis of different related factors}

We evaluate the surgical outcomes of patients according to different related factors, including the extent of resection, age, BMI, depth of invasion, and tumor size. The surgical outcomes of subgroup analyses are summarized in Tables 4-8. The results indicated that the RG groups had less intraoperative blood loss in all subgroup analyses $(P<0.05)$. However, $\mathrm{RG}$ was associated with longer operation time and higher cost in all subgroup analysis. RG had more harvested lymph nodes 
Table 2 Surgical outcomes and postoperative complications

\begin{tabular}{|c|c|c|c|}
\hline Characteristics & $R G(n=|| 2)$ & LG $(n=\mid 12)$ & $P$-value \\
\hline Operation time (min) & $261.7 \pm 63.9$ & $227.8 \pm 45.8$ & 0.000 \\
\hline Estimated blood loss (mL) & $179.2 \pm 66.8$ & $234.8 \pm 139.5$ & 0.000 \\
\hline No. of retrieved lymph nodes & $29.5 \pm 9.6$ & $27.7 \pm 8.7$ & 0.149 \\
\hline Time to first flatus (d) & $2.6 \pm 0.6$ & $2.8 \pm 1.1$ & 0.124 \\
\hline Time to start liquid diet (d) & $1.6 \pm 0.7$ & $1.7 \pm 0.5$ & 0.320 \\
\hline Time to start soft diet (d) & $3.6 \pm 1.6$ & $3.9 \pm 2.0$ & 0.179 \\
\hline Postoperative hospital stay (d) & $6.9 \pm 2.3$ & $7.0 \pm 3.8$ & 0.718 \\
\hline Cost of hospitalization (RMB) & $92,365.0 \pm 6015.0$ & $69,476.5 \pm 5885.6$ & 0.000 \\
\hline Overall complications (\%) & $15(13.4)$ & $13(11.6)$ & 0.686 \\
\hline Grade II (\%) & $7(6.3)$ & $6(5.4)$ & 0.775 \\
\hline Wound infection & 2 & I & 1.000 \\
\hline Pneumonia & 2 & I & 1.000 \\
\hline Pancreatitis & I & 0 & 1.000 \\
\hline Severe anemia & 2 & 4 & 0.683 \\
\hline Grade IIla (\%) & $4(3.6)$ & $5(4.5)$ & 1.000 \\
\hline Wound problem & 0 & I & 1.000 \\
\hline Abdominal infection & 2 & 0 & 0.478 \\
\hline Anastomosis leakage & I & 2 & 1.000 \\
\hline Duodenal stump fistula & I & 2 & 1.000 \\
\hline Grade IIIb (\%) & $2(1.8)$ & $\mathrm{I}(0.9)$ & 1.000 \\
\hline Intra-abdominal bleeding & 0 & $\mathrm{I}$ & 1.000 \\
\hline Anastomosis bleeding & 2 & 0 & 0.478 \\
\hline Grade IV (\%) & $2(1.8)$ & $\mathrm{I}(0.9)$ & 1.000 \\
\hline Heart failure & I & 0 & 1.000 \\
\hline Respiratory failure & I & I & 1.000 \\
\hline Grade V (\%) & $0(0.0)$ & $0(0.0)$ & - \\
\hline Clavien-Dindo grade $\geq$ Illa (\%) & $8(7.1)$ & $7(6.3)$ & 0.789 \\
\hline
\end{tabular}

Note: Data are presented as mean \pm standard deviation.

Abbreviations: d, days; LG, laparoscopic gastrectomy; RG, robotic gastrectomy.

Table 3 Comparison of the 2 surgery methods in different phases

\begin{tabular}{|c|c|c|c|c|c|c|}
\hline \multirow[t]{2}{*}{ Variables } & \multicolumn{3}{|l|}{ Initial phase } & \multicolumn{3}{|l|}{ Late phase } \\
\hline & RG $(n=56)$ & LG $(n=56)$ & $P$-value & RG (n=56) & LG $(n=56)$ & $P$-value \\
\hline Age (years) & $54.4 \pm 11.1$ & $56.4 \pm 11.7$ & 0.351 & $56.8 \pm I I .4$ & $55.9 \pm 10.6$ & 0.643 \\
\hline Gender (male/female) & $38 / 18$ & $42 / 14$ & 0.403 & $40 / 16$ & $37 / 19$ & $0.54 I$ \\
\hline Body mass index & $23.9 \pm 2.4$ & $23.4 \pm 3.0$ & 0.323 & $23.3 \pm 3.3$ & $23.7 \pm 3.1$ & 0.546 \\
\hline Comorbidity (present/absent) & $10 / 46$ & $13 / 43$ & 0.483 & $13 / 43$ & $\mathrm{I} \mid / 45$ & 0.645 \\
\hline Extent of resection (DG/TG) & $31 / 25$ & $33 / 23$ & 0.703 & $35 / 21$ & $33 / 23$ & 0.699 \\
\hline Operation time $(\mathrm{min})$ & $286.0 \pm 57.7$ & $236.9 \pm 48.7$ & 0.000 & $237.4 \pm 60.9$ & $218.8 \pm 41.0$ & 0.060 \\
\hline Estimated blood loss (mL) & $183.9 \pm 75.6$ & $243.8 \pm 141.0$ & 0.006 & $174.5 \pm 56.9$ & $225.9 \pm 138.7$ & 0.012 \\
\hline No. of retrieved lymph nodes & $29.6 \pm 8.1$ & $26.6 \pm 7.2$ & 0.042 & $29.4 \pm 10.9$ & $28.8 \pm 9.9$ & 0.779 \\
\hline Time to first flatus (days) & $2.6 \pm 0.6$ & $2.8 \pm 1.1$ & 0.124 & $2.6 \pm 0.5$ & $2.7 \pm 0.4$ & 0.261 \\
\hline Time to start liquid diet (days) & $1.6 \pm 0.7$ & $1.7 \pm 0.5$ & 0.320 & $1.6 \pm 0.7$ & $1.6 \pm 0.5$ & 0.675 \\
\hline Time to start soft diet (days) & $3.6 \pm 2.0$ & $3.9 \pm 2.0$ & 0.179 & $3.4 \pm 1.2$ & $3.6 \pm 0.9$ & 0.470 \\
\hline Postoperative hospital stay (days) & $6.9 \pm 2.3$ & $7.0 \pm 3.8$ & 0.718 & $6.9 \pm 2.2$ & $6.4 \pm 2.3$ & 0.254 \\
\hline Cost of hospitalization (RMB) & $92,906.1 \pm 5288.7$ & $69,924.2 \pm 5980.0$ & 0.000 & $91,824.0 \pm 6667.3$ & $69,028.8 \pm 5808.8$ & 0.000 \\
\hline
\end{tabular}

Note: Data are presented as mean \pm standard deviation.

Abbreviations: DG, distal gastrectomy; LG, laparoscopic gastrectomy; RG, robotic gastrectomy; TG, total gastrectomy.

in patients who underwent DG $(28.77 \pm 11.00$ vs $24.8 \pm 7.0$, $P=0.014)$ and patients with low BMI (29.0 \pm 8.6 vs $26.0 \pm 6.9$, $P=0.026)$. However, no statistical significant differences were observed in the comparison of other subgroups. No differences were found between the 2 groups regarding the time to first flatus, time to start liquid diet, postoperative hospital stay, and incidence of overall postoperative complications.

\section{Follow-up result}

Within a median follow-up period of 28 months (range 3-52 months), the recurrence rate was $18.8 \%$ (21/112) in the RG group and $21.4 \%(24 / 112)$ in the LG group, with no significant difference $(P=0.617)$. The 3 -year OS rates of the RG and LG groups were $78.6 \%$ and $74.1 \%(P=0.483$, Figure 1). Stratified analysis showed that the 3 -year OS rates 
Table 4 Comparison of the 2 surgery methods in different resection extent

\begin{tabular}{|c|c|c|c|c|c|c|}
\hline \multirow[t]{2}{*}{ Variables } & \multicolumn{3}{|c|}{ Distal gastrectomy } & \multicolumn{3}{|c|}{ Total gastrectomy } \\
\hline & RG $(n=66)$ & LG $(n=66)$ & $P$-value & RG (n=46) & LG $(n=46)$ & $P$-value \\
\hline Age (years) & $55.2 \pm \mathrm{I} 1.6$ & $54.1 \pm 54.1$ & 0.593 & $56.2 \pm 10.8$ & $59.0 \pm 10.5$ & 0.360 \\
\hline Gender (male/female) & $48 / 18$ & $48 / 18$ & 1.000 & $30 / 16$ & $31 / 15$ & 0.825 \\
\hline Body mass index & $23.2 \pm 3.0$ & $23.3 \pm 3.1$ & 0.950 & $24.2 \pm 2.7$ & $24.0 \pm 2.9$ & 0.704 \\
\hline Comorbidity (present/absent) & $14 / 52$ & $10 / 56$ & 0.367 & $9 / 37$ & $14 / 32$ & 0.229 \\
\hline Operation time (min) & $220.5 \pm 29.9$ & $198.1 \pm 25.0$ & 0.000 & $320.8 \pm 52.1$ & $270.5 \pm 33.1$ & 0.000 \\
\hline Estimated blood loss (mL) & $160.0 \pm 57.0$ & $221.3 \pm 133.0$ & 0.001 & $206.7 \pm 70.6$ & $254.1 \pm 147.7$ & 0.053 \\
\hline No. of retrieved lymph nodes & $28.8 \pm 11.0$ & $24.8 \pm 7.0$ & 0.014 & $30.6 \pm 7.0$ & $32.0 \pm 9.1$ & 0.406 \\
\hline Time to first flatus (days) & $2.5 \pm 0.7$ & $2.6 \pm 1.1$ & 0.489 & $2.8 \pm 0.5$ & $3.1 \pm 1.1$ & 0.086 \\
\hline Time to start liquid diet (days) & $1.5 \pm 0.5$ & $1.6 \pm 0.4$ & 0.372 & $1.8 \pm 0.8$ & $1.9 \pm 0.6$ & 0.533 \\
\hline Time to start soft diet (days) & $3.4 \pm 1.6$ & $3.7 \pm 2.1$ & 0.267 & $3.9 \pm 1.6$ & $4.2 \pm 1.8$ & 0.439 \\
\hline Postoperative hospital stay (days) & $6.6 \pm 2.3$ & $6.7 \pm 2.3$ & 0.820 & $7.3 \pm 2.3$ & $7.6 \pm 5.2$ & 0.777 \\
\hline Overall complications (\%) & $7(10.6)$ & $7(10.6)$ & 1.000 & $8(17.4)$ & $6(13.0)$ & 0.562 \\
\hline Cost of hospitalization (RMB) & $89,274.7 \pm 4848.6$ & $66,178.0 \pm 4072.8$ & 0.000 & $96,769.0 \pm 4602.7$ & $74,209.1 \pm 4758.6$ & 0.000 \\
\hline
\end{tabular}

Note: Data are presented as mean \pm standard deviation.

Abbreviations: LG, laparoscopic gastrectomy; RG, robotic gastrectomy.

Table 5 Comparison of the 2 surgery methods in different age groups

\begin{tabular}{|c|c|c|c|c|c|c|}
\hline \multirow[t]{2}{*}{ Variables } & \multicolumn{3}{|l|}{ Age $\leq 60$} & \multicolumn{3}{|l|}{ Age $>60$} \\
\hline & RG $(n=69)$ & LG $(n=69)$ & $P$-value & RG $(n=43)$ & LG $(n=43)$ & $P$-value \\
\hline Gender (male/female) & $46 / 23$ & $49 / 20$ & 0.581 & $32 / 11$ & $30 / 13$ & 0.631 \\
\hline Body mass index & $23.7 \pm 3.0$ & $24.0 \pm 3.0$ & 0.546 & $23.5 \pm 2.7$ & $22.8 \pm 3.0$ & 0.264 \\
\hline Comorbidity (present/absent) & $6 / 63$ & $5 / 64$ & 0.753 & $17 / 26$ & $19 / 24$ & 0.662 \\
\hline Operation time $(\mathrm{min})$ & $258.7 \pm 63.5$ & $222.9 \pm 42.6$ & 0.000 & $266.6 \pm 65.0$ & $235.7 \pm 49.9$ & 0.015 \\
\hline Estimated blood loss (mL) & $174.9 \pm 61.3$ & $208.8 \pm 96.9$ & 0.015 & $186 . \mid \pm 75.0$ & $276.5 \pm 182.6$ & 0.004 \\
\hline No. of retrieved lymph nodes & $27.9 \pm 10.2$ & $26.4 \pm 7.7$ & 0.334 & $32.1 \pm 7.9$ & $29.8 \pm 9.8$ & 0.252 \\
\hline Time to first flatus (days) & $2.4 \pm 0.6$ & $2.5 \pm 0.4$ & 0.527 & $3.0 \pm 0.5$ & $3.4 \pm 1.6$ & 0.122 \\
\hline Time to start liquid diet (days) & $1.5 \pm 0.7$ & $1.5 \pm 0.4$ & 0.908 & $1.8 \pm 0.5$ & $2.0 \pm 0.6$ & 0.112 \\
\hline Time to start soft diet (days) & $3.4 \pm 1.4$ & $3.4 \pm 0.5$ & 0.929 & $3.9 \pm 1.8$ & $4.7 \pm 3.0$ & 0.129 \\
\hline Postoperative hospital stay (days) & $6.7 \pm 2.1$ & $6.4 \pm 2.1$ & 0.437 & $7.1 \pm 2.7$ & $8.0 \pm 5.4$ & 0.367 \\
\hline Overall complications (\%) & $5(7.2)$ & $4(5.8)$ & 0.730 & $10(23.3)$ & $9(20.9)$ & 0.795 \\
\hline Cost of hospitalization (RMB) & $91,567.8 \pm 5510.0$ & $68,331.3 \pm 4918.3$ & 0.000 & $93,644.2 \pm 66 \mid 4.1$ & $7|, 3| 4.1 \pm 6839.0$ & 0.000 \\
\hline
\end{tabular}

Note: Data are presented as mean \pm standard deviation.

Abbreviations: LG, laparoscopic gastrectomy; RG, robotic gastrectomy.

Table 6 Comparison of the 2 surgery methods in different body mass index

\begin{tabular}{|c|c|c|c|c|c|c|}
\hline \multirow[t]{2}{*}{ Variables } & \multicolumn{3}{|l|}{ BMI $<25$} & \multicolumn{3}{|l|}{$B M I \geq 25$} \\
\hline & RG (n=72) & LG $(n=68)$ & $P$-value & RG $(n=40)$ & LG $(n=44)$ & $P$-value \\
\hline Age (years) & $56.8 \pm 11.2$ & $57.8 \pm \mid 1.0$ & 0.621 & $53.4 \pm I \mid .2$ & $53.6 \pm 10.8$ & 0.360 \\
\hline Gender (male/female) & $50 / 22$ & $49 / 19$ & 0.734 & $28 / 12$ & $30 / 14$ & 0.857 \\
\hline Comorbidity (present/absent) & $19 / 53$ & $14 / 54$ & 0.419 & $4 / 36$ & $10 / 34$ & 0.118 \\
\hline Operation time $(\mathrm{min})$ & $261.9 \pm 68.6$ & $224.5 \pm 46.5$ & 0.000 & $261.3 \pm 55.3$ & $233.0 \pm 44.7$ & 0.011 \\
\hline Estimated blood loss (mL) & $|8| .0 \pm 70.2$ & $232.7 \pm 133.1$ & 0.004 & $176.0 \pm 60.8$ & $238.2 \pm 150.3$ & 0.017 \\
\hline No. of retrieved lymph nodes & $29.0 \pm 8.6$ & $26.0 \pm 6.9$ & 0.026 & $30.5 \pm 11.2$ & $30.4 \pm 10.4$ & 0.066 \\
\hline Time to first flatus (days) & $2.6 \pm 0.6$ & $2.8 \pm 1.1$ & 0.187 & $2.7 \pm 0.7$ & $2.9 \pm 1.1$ & 0.440 \\
\hline Time to start liquid diet (days) & $1.6 \pm 0.7$ & $1.7 \pm 0.6$ & 0.680 & $1.6 \pm 0.5$ & $1.7 \pm 0.5$ & 0.231 \\
\hline Time to start soft diet (days) & $3.6 \pm 1.6$ & $4.0 \pm 2.3$ & 0.260 & $3.5 \pm 1.5$ & $3.8 \pm 1.4$ & 0.442 \\
\hline Postoperative hospital stay (days) & $7.1 \pm 2.6$ & $6.7 \pm 2.6$ & 0.378 & $6.5 \pm 1.5$ & $7.5 \pm 5.1$ & 0.217 \\
\hline Overall complications (\%) & $10(13.9)$ & $8(11.8)$ & 0.707 & $5(12.5)$ & $5(11.4)$ & 0.860 \\
\hline Cost of hospitalization (RMB) & $92,660.0 \pm 5997.1$ & $69,447.0 \pm 6138.0$ & 0.000 & $91,834.0 \pm 6086.9$ & $69,522.1 \pm 5541.9$ & 0.000 \\
\hline
\end{tabular}

Note: Data are presented as mean \pm standard deviation.

Abbreviations: BMI, body mass index; LG, laparoscopic gastrectomy; RG, robotic gastrectomy.

for the patients after RG and LG were as follows: a total of $\quad(P=0.667$, Figure $2 \mathrm{~B})$, and $70.8 \%$ vs $64.0 \%$ for the patients $90.0 \%$ vs $94.4 \%$ for the patients with stage IB $(P=0.436$, with stage III ( $P=0.687$, Figure $2 \mathrm{C})$. Comparisons of the OS Figure $2 \mathrm{~A}$ ), $81.8 \%$ vs $77.3 \%$ for the patients with stage II rates did not show significant difference for any of the stages. 
Table 7 Comparison of the 2 surgery methods in different depth of invasion

\begin{tabular}{|c|c|c|c|c|c|c|}
\hline \multirow[t]{2}{*}{ Variables } & \multicolumn{3}{|c|}{ No serosa invasion } & \multicolumn{3}{|l|}{ Serosa invasion } \\
\hline & RG $(n=38)$ & LG $(n=36)$ & $P$-value & RG $(n=74)$ & LG $(n=76)$ & $P$-value \\
\hline Age (years) & $55.8 \pm 12.5$ & $56.2 \pm 12.6$ & 0.890 & $55.5 \pm 10.7$ & $56.1 \pm 10.4$ & 0.732 \\
\hline Gender (male/female) & $26 / 12$ & $24 / 12$ & 0.872 & $52 / 22$ & $55 / 21$ & 0.776 \\
\hline Body mass index & $24.1 \pm 2.8$ & $24.0 \pm 2.7$ & 0.989 & $23.4 \pm 2.9$ & $23.3 \pm 3.2$ & 0.866 \\
\hline Comorbidity (present/absent) & $7 / 31$ & $9 / 27$ & 0.492 & $58 / 16$ & $61 / 15$ & 0.776 \\
\hline Operation time $(\mathrm{min})$ & $280.7 \pm 71.1$ & $242.4 \pm 51.3$ & 0.010 & $252.0 \pm 58.0$ & $221.0 \pm 41.5$ & 0.000 \\
\hline Estimated blood loss (mL) & $178.2 \pm 65.8$ & $258.3 \pm 159.0$ & 0.006 & $179.7 \pm 67.7$ & $223.7 \pm 128.9$ & 0.010 \\
\hline No. of retrieved lymph nodes & $30.5 \pm 10.7$ & $30.8 \pm 9.0$ & 0.896 & $29.0 \pm 9.0$ & $26.3 \pm 8.3$ & 0.055 \\
\hline Time to first flatus (days) & $2.7 \pm 0.8$ & $2.8 \pm 0.7$ & 0.465 & $2.6 \pm 0.6$ & $2.8 \pm 1.3$ & 0.176 \\
\hline Time to start liquid diet (days) & $1.8 \pm 1.0$ & $1.7 \pm 0.5$ & $0.88 \mathrm{I}$ & $1.6 \pm 0.4$ & $1.7 \pm 0.6$ & 0.096 \\
\hline Time to start soft diet (days) & $3.6 \pm 2.2$ & $3.7 \pm 1.2$ & 0.771 & $3.6 \pm 1.2$ & $4.0 \pm 2.2$ & 0.154 \\
\hline Postoperative hospital stay (days) & $7.2 \pm 3.2$ & $7.0 \pm 4.0$ & 0.777 & $6.7 \pm 1.7$ & $7.1 \pm 3.7$ & 0.462 \\
\hline Overall complications (\%) & $7(18.4)$ & $4(11.1)$ & 0.376 & $8(10.8)$ & $9(11.8)$ & 0.842 \\
\hline Cost of hospitalization (RMB) & $92,932.9 \pm 6380.2$ & $70,763.1 \pm 5555.6$ & 0.000 & $92,073.4 \pm 5841.9$ & $68,867.0 \pm 5974.4$ & 0.000 \\
\hline
\end{tabular}

Note: Data are presented as mean \pm standard deviation.

Abbreviations: LG, laparoscopic gastrectomy; RG, robotic gastrectomy.

Table 8 Comparison of the 2 surgery methods in different tumor size

\begin{tabular}{|c|c|c|c|c|c|c|}
\hline \multirow[t]{2}{*}{ Variables } & \multicolumn{3}{|c|}{ Tumor size $\leq 5 \mathrm{~cm}$} & \multicolumn{3}{|c|}{ Tumor size $>5 \mathrm{~cm}$} \\
\hline & RG (n=83) & LG $(n=84)$ & $P$-value & RG $(n=29)$ & LG $(n=28)$ & $P$-value \\
\hline Age (years) & $54.7 \pm 11.6$ & $54.9 \pm 11.0$ & 0.917 & $58.1 \pm 10.1$ & $59.8 \pm 10.8$ & 0.545 \\
\hline Gender (male/female) & $57 / 26$ & $62 / 22$ & 0.463 & $21 / 8$ & $|7 /| \mid$ & 0.349 \\
\hline Body mass index & $23.7 \pm 3.0$ & $23.7 \pm 3.0$ & 0.953 & $23.4 \pm 2.5$ & $23.1 \pm 3.2$ & 0.621 \\
\hline Comorbidity (present/absent) & $15 / 68$ & $16 / 68$ & $0.87 \mid$ & $8 / 21$ & $8 / 20$ & 0.934 \\
\hline Operation time (min) & $248.8 \pm 60.8$ & $219.5 \pm 41.3$ & 0.000 & $298.5 \pm 58.8$ & $252.8 \pm 50.1$ & 0.003 \\
\hline Estimated blood loss (mL) & $171.5 \pm 6 \mid .9$ & $232.6 \pm 141.6$ & 0.000 & $201.4 \pm 76.0$ & $24 I .4 \pm 135.4$ & 0.172 \\
\hline No. of retrieved lymph nodes & $28.2 \pm 9.9$ & $27.0 \pm 8.5$ & 0.399 & $33.2 \pm 7.4$ & $30.0 \pm 9.1$ & 0.140 \\
\hline Time to first flatus (days) & $2.6 \pm 0.7$ & $2.7 \pm 1.1$ & 0.347 & $2.8 \pm 0.5$ & $3.1 \pm 1.2$ & 0.144 \\
\hline Time to start liquid diet (days) & $1.6 \pm 0.7$ & $1.7 \pm 0.5$ & 0.953 & $1.6 \pm 0.4$ & $1.9 \pm 0.7$ & 0.052 \\
\hline Time to start soft diet (days) & $3.6 \pm 1.8$ & $3.8 \pm 1.3$ & 0.389 & $3.4 \pm 0.7$ & $4.1 \pm 2.1$ & 0.119 \\
\hline Postoperative hospital stay (days) & $6.9 \pm 2.6$ & $6.8 \pm 3.1$ & 0.810 & $6.8 \pm 1.5$ & $7.7 \pm 5.4$ & 0.378 \\
\hline Overall complications (\%) & II (I3.3) & $8(9.5)$ & 0.448 & $4(13.8)$ & $5(17.9)$ & 0.954 \\
\hline Cost of hospitalization (RMB) & $91,300.9 \pm 6265.8$ & $68,616.0 \pm 5675.8$ & 0.000 & $95,410.6 \pm 3935.9$ & $72,058.0 \pm 5845.2$ & 0.000 \\
\hline
\end{tabular}

Note: Data are presented as mean \pm standard deviation.

Abbreviations: LG, laparoscopic gastrectomy; RG, robotic gastrectomy.

\section{Discussion}

To date, a considerable number of studies have investigated the short-term outcomes of RG for gastric cancer. ${ }^{15-18}$ However, the majority of these studies included patients at a relatively early stage, and few of them evaluated the outcomes of RG for AGC. Thus, we designed this study to compare the short- and long-term outcomes of RG and LG for AGC. Additionally, we used the propensity score-matching method to reduce bias.

In the present study, we observed that the RG group was associated with less blood loss compared with the LG group, which is consistent with the previous studies. Moreover, this advantage still exists when subgroup analysis was conducted. Junfeng et $\mathrm{l}^{19}$ reported that the $\mathrm{RG}$ group had less intraoperative blood loss (101.4 vs $131.4 \mathrm{~mL}, P=0.017)$ and more harvested lymph nodes ( $34.6 \pm 10.9$ vs $32.7 \pm 11.2, P=0.013$ ) compared with the LG group. This could be attributed to the fact that RG has tremor filtration, the ability to scale motion, and is stereoscopic, which could improve a surgeon's dexterity, allow precise dissection, and avoid injury blood vessels. Our result showed a tendency favoring RG in terms of the number of harvested lymph nodes, although no significant difference was observed between the RG and LG groups.

Lymph node dissection is one of the key elements of radical gastrectomy. It has been reported that the number of lymph node dissection was related to patients' prognosis. ${ }^{20-23}$ From the standpoint of AGC curability, gastrectomy with D2 lymph node dissection is required according to the Japanese Gastric Cancer Association guidelines. ${ }^{24-26}$ However, the superiority of more harvested lymph nodes was not consistent among all studies. Pugliese et $\mathrm{a}^{27}$ and Song et $\mathrm{al}^{28}$ reported that the number of harvested lymph 


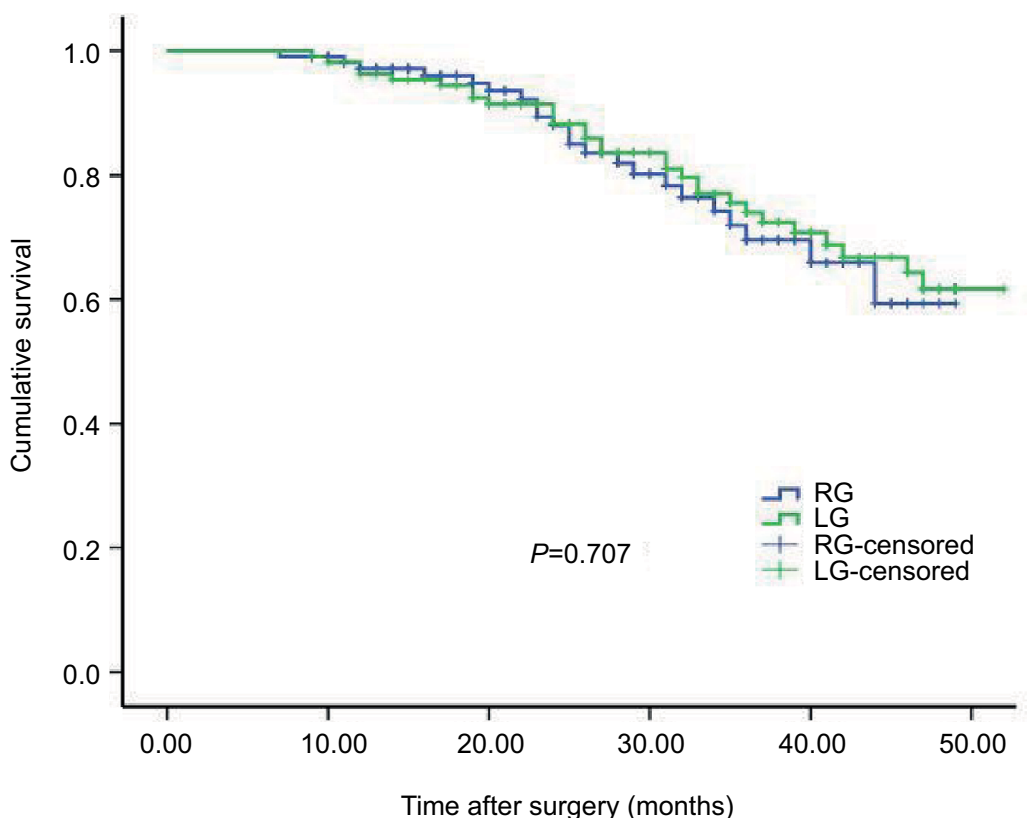

Figure I Kaplan-Meier curves of overall survival for all patients. Abbreviations: LG, laparoscopic gastrectomy; RG, robotic gastrectomy.

nodes in the RG group are less than those in the LG group, but these studies are in small sample size and the result was drawn from their initial experience. In addition, studies have demonstrated that surgeons become skilled in RG with the accumulation of experience of about 20-30 cases, which provides a short learning curve compared with LG. ${ }^{29-33}$ Several meta-analyses revealed that harvested lymph nodes for RG and LG were similar, but they all showed a tendency favoring RG..$^{17,34,35}$ According to our experience, the advantage of RG is that it could enable the surgeons to perform more precise dissection and anastomoses. These superiorities are more obvious for difficult lymph node dissection (station 8a, 10,11p, 12a), which remains the cornerstone of D2 lymphadenectomy. Moreover, the robotic system can provide a much more stable view and better exposure in narrow operating field. Regarding more complex surgery, such as the resection of gastric stump cancer, the robotic surgical system has the advantages of clear vision, flexible operation, and stable traction during the operation procedure, which is superior to the laparoscopic technique.

Postoperative complication is an important factor for evaluating the safety and feasibility of a surgical procedure. We evaluate the postoperative complications according the Clavien-Dindo classification system, which has proven to be a standardized classification for assessment for complications in many types of surgery. In the current study, we found that the incidences of overall complications were comparable between the RG and LG groups ( $13.4 \%$ vs $11.6 \%, P=0.686$ ).
Moreover, no significant differences were noted in the minor (Clavien-Dindo grade II) and major complication (ClavienDindo grade $\geq$ IIIa) rates between the 2 groups $(6.8 \%$ vs $5.4 \%, P=0.775 ; 4.8 \%$ vs $6.8 \%, P=0.453$; respectively). Furthermore, analyses of specified complications revealed that the rate of wound problem, anastomotic leakage, duodenal stump fistula, and abdominal infection were also similar between the 2 groups.

The extent of resection, age, BMI, depth of invasion, and tumor size could be factors associated with the shortterm outcomes. ${ }^{36-38}$ In this study, we performed analyses by grouping the patients according to different factors. We found that patients in the RG group were all associated with lower blood loss. Intraoperative blood loss has been shown to be associated with prognosis of patients in gastric cancer. ${ }^{39,40}$ Kamei et al reported that curative resection with lower blood loss can contribute to improved survival. ${ }^{41}$ Moreover, the less intraoperative blood loss may promote postoperative recovery, especially for elderly patients. Our result revealed that RG patients had a tendency to recover fast after surgery, although no significant differences were found in respect of these indicators. Lee et $\mathrm{al}^{7}$ reported that the superiority of RG was more obvious in high BMI patients when performing DG. In the present study, among patients in the high BMI group, RG was also associated with less intraoperative blood loss. Meanwhile, the RG group was comparable with the LG group in terms of other surgical outcomes. According to the present findings, it seems that optimal surgical 

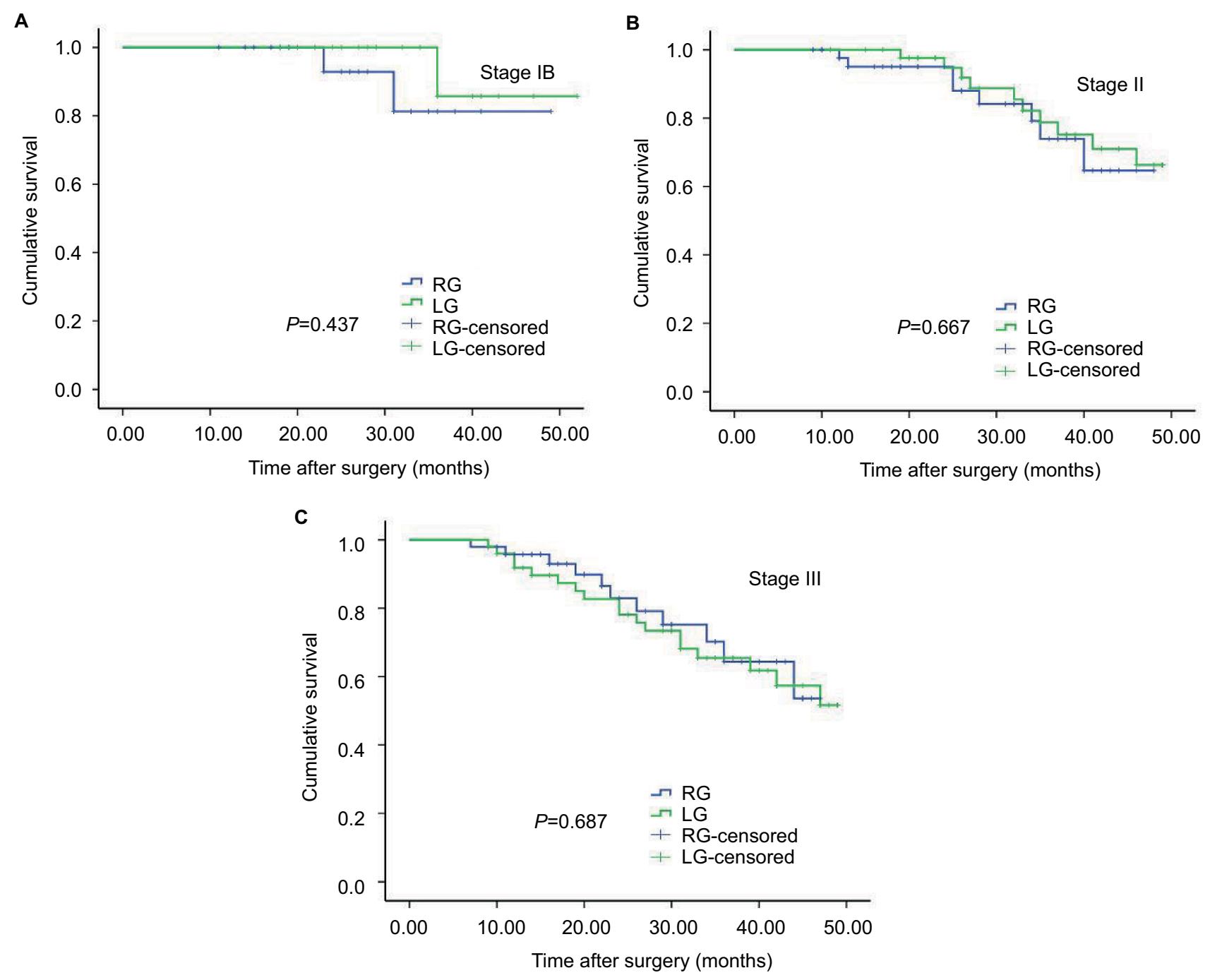

Figure 2 Kaplan-Meier curves of overall survival (A) patients in stage IB (B) patients in stage II (C) patients in stage III. Abbreviations: LG, laparoscopic gastrectomy; RG, robotic gastrectomy.

outcomes may have already been achieved with LG, leaving little room for improvement via RG. Enhanced recovery after surgery protocols has been routinely applied to accelerate the postoperative recovery of patients with gastric cancer in our center since 2012, which could explain that the time to first flatus, time to start diet, and postoperative hospital stay were superior to those reported in previous studies. ${ }^{17,42}$

Long-term survival outcomes are key indicator for assessing oncological safety. Therefore, the long-term outcomes are also important and necessary for the wide application of $\mathrm{RG}$ in AGC. Junfeng et a ${ }^{19}$ reported that the 3 -year OS rates of patients with gastric cancer in RG and LG groups were $68.1 \%$ and $63.7 \%$, respectively, with a median follow-up of 17 months; the difference was not statistically significant. In a propensity-matched analysis of RG vs LG for gastric cancer from 2005 to 2009 , no significant differences were found in 5-year OS rate $(93.2 \%$ vs $94.2 \%, P=0.521)$ and disease-free survival rate $(90.7 \%$ vs $92.6 \%, P=0.229)$ with a median follow-up of 85 months. However, patients in early stage account for $83.4 \%$ in the study reported by Obama et al. ${ }^{43}$ In the present study, patients in stages II and III account for $83.0 \%$ of all cases in propensity score-matched cohort, indicating a poor prognosis for these cases. The current study showed that the 3-year OS rate after RG was similar with those in LG with a median follow-up of 28 months (78.6\% vs $74.1 \%, P=0.483)$. Regarding stratified stages, the 3 -year OS was also comparable between the 2 groups. These results indicated that $\mathrm{RG}$ and $\mathrm{LG}$ had comparable long-term survival outcomes for AGC.

Financial cost may also be an important factor in driving the selection of surgery type. ${ }^{44,45}$ To examine cost-effectiveness of the RG and LG, we retrospectively reviewed the overall hospital expenditure and found that the cost of RG group was about 23,000 RMB more than that of the LG group. A recent 
meta-analysis reported that the RG groups cost about $\$ 4000$ more than the LG groups. In our clinical practice, the higher cost, longer operation time, and limited benefit to patients are the major stumbling block to the wide application of RG. Meanwhile, the long-term benefits of less intraoperative blood loss have not been proven yet. Additionally, there is also no published study about the quality of life after RG, which is often used to assess the surgical outcomes. ${ }^{46,47}$ We believe that these problems will be solved in the near future with the accumulation of surgeon's experience, reduced costs of surgery, and more high-quality research on this topic.

We admit that our study has several limitations. First, this is a retrospective study conducted at a single center with limited duration of follow-up. Additionally, the allocation of the operation method to either RG or LG may include a selection bias, which could not be offset by propensity score-matching method.

\section{Conclusion}

RG with D2 lymph node dissection is safe and feasible for AGC in terms of both short- and long-term outcomes. The higher cost, longer operation time, and limited benefit are the major stumbling blocks to the wide application of $\mathrm{RG}$. High-volume randomized controlled trials with sufficient follow-up are needed to confirm this rationale.

\section{Acknowledgments}

The authors are thankful to medical staff of Xijing Hospital of Digestive Diseases for their management of database. This study was supported by the National Key Basic Research Program of China (No. 2014CBA02002).

\section{Disclosure}

The authors report no conflicts of interest in this work.

\section{References}

1. Chen W, Zheng R, Baade PD, et al. Cancer statistics in China, 2015. CA Cancer J Clin. 2016;66(2):115-132.

2. Li HZ, Chen JX, Zheng Y, Zhu XN. Laparoscopic-assisted versus open radical gastrectomy for resectable gastric cancer: Systematic review, meta-analysis, and trial sequential analysis of randomized controlled trials. J Surg Oncol. 2016;113(7):756-767.

3. Kim HH, Hyung WJ, Cho GS, et al. Morbidity and mortality of laparoscopic gastrectomy versus open gastrectomy for gastric cancer: an interim report-a phase III multicenter, prospective, randomized Trial (KLASS Trial). Ann Surg. 2010;251(3):417-420.

4. Vinuela EF, Gonen M, Brennan MF, Coit DG, Strong VE. Laparoscopic versus open DG for gastric cancer: a meta-analysis of randomized controlled trials and high-quality nonrandomized studies. Ann Surg. 2012;255(3):446-456.
5. Jiang L, Yang KH, Guan QL, et al. Laparoscopy-assisted gastrectomy versus open gastrectomy for resectable gastric cancer: an update meta-analysis based on randomized controlled trials. Surg Endosc. 2013;27(7):2466-2480.

6. Katai H, Mizusawa J, Katayama H, et al. Short-term surgical outcomes from a phase III study of laparoscopy-assisted versus open DG with nodal dissection for clinical stage IA/IB gastric cancer: Japan Clinical Oncology Group Study JCOG0912. Gastric Cancer. 2017;20(4): 699-708.

7. Lee J, Kim YM, Woo Y, Obama K, Noh SH, Hyung WJ. Robotic distal subtotal gastrectomy with D2 lymphadenectomy for gastric cancer patients with high body mass index: comparison with conventional laparoscopic distal subtotal gastrectomy with D2 lymphadenectomy. Surg Endosc. 2015;29(11):3251-3260.

8. Son T, Hyung WJ. Robotic gastrectomy for gastric cancer. J Surg Oncol. 2015;112(3):271-278.

9. Terashima M, Tokunaga M, Tanizawa $Y$, et al. Robotic surgery for gastric cancer. Gastric Cancer. 2015;18(3):449-457.

10. Kim YM, Son T, Kim HI, Noh SH, Hyung WJ. Robotic D2 lymph node dissection during distal subtotal gastrectomy for gastric cancer: toward procedural standardization. Ann Surg Oncol. 2016;23(8):2409-2410.

11. Sano T, Coit DG, Kim HH, et al. Proposal of a new stage grouping of gastric cancer for TNM classification: International Gastric Cancer Association staging project. Gastric Cancer. 2017;20(2):217-225.

12. Clavien PA, Barkun J, de Oliveira ML, et al. The Clavien-Dindo classification of surgical complications: 5-year experience. Ann Surg. 2009;250(2):187-196.

13. Dindo D, Demartines N, Clavien PA. Classification of surgical complications. Ann Surg. 2004;240(2):205-213.

14. Japanese Gastric Cancer Association. Japanese gastric cancer treatment guidelines 2010 (ver. 3). Gastric Cancer. 2011;14(2):113-123.

15. Huang KH, Lan YT, Fang WL, et al. Initial experience of robotic gastrectomy and comparison with open and laparoscopic gastrectomy for gastric cancer. J Gastrointest Surg. 2012;16(7):1303-1310.

16. Shen W, Xi H, Wei B, et al. Robotic versus laparoscopic gastrectomy for gastric cancer: comparison of short-term surgical outcomes. Surg Endosc. 2016;30(2):574-580.

17. Chen K, Pan Y, Zhang B, Maher H, Wang XF, Cai XJ. Robotic versus laparoscopic Gastrectomy for gastric cancer: a systematic review and updated meta-analysis. BMC Surg. 2017;17(1):93.

18. Yang SY, Roh KH, Kim YN, et al. Surgical outcomes after open, laparoscopic, and robotic gastrectomy for gastric cancer. Ann Surg Oncol. 2017;24(7):1770-1777.

19. Junfeng Z, Yan S, Bo T, et al. Robotic gastrectomy versus laparoscopic gastrectomy for gastric cancer: comparison of surgical performance and short-term outcomes. Surg Endosc. 2014;28(6):1779-1787.

20. Songun I, Putter H, Kranenbarg EM. Surgical treatment of gastric cancer: 15-year follow-up results of the randomised nationwide Dutch D1D2 trial. Lancet Oncol. 2010;11(5):439-449.

21. Jiao XG, Deng JY, Zhang RP, et al. Prognostic value of number of examined lymph nodes in patients with node-negative gastric cancer. World J Gastroenterol. 2014;20(13):3640-3648.

22. Gholami S, Janson L, Worhunsky DJ, et al. Number of lymph nodes removed and survival after gastric cancer resection: an analysis from the US gastric cancer collaborative. J Am Coll Surg. 2015;221(2): 291-299.

23. Chen XZ Yang K, Zhang B, Hu JK, Zhou C. Is retrieval of $>25$ lymph nodes a superior criterion for locally advanced gastric cancer surgery? Ann Surg. 2011;254(5):834-835.

24. Tanizawa Y, Terashima M. Lymph node dissection in the resection of gastric cancer: review of existing evidence. Gastric Cancer. 2010;13(3):137-348.

25. Hamabe A, Omori T, Tanaka K, Nishida T. Comparison of long-term results between laparoscopy-assisted gastrectomy and open gastrectomy with D2 lymph node dissection for advanced gastric cancer. Surg Endosc. 2012;26(6):1702-1709. 
26. Saka M, Morita S, Fukagawa T, Katai H. Present and future status of gastric cancer surgery. Jpn J Clin Oncol. 2011;41(3):307-313.

27. Pugliese R, Maggioni D, Sansonna F, et al. Outcomes and survival after laparoscopic gastrectomy for adenocarcinoma. Analysis on 65 patients operated on by conventional or robot-assisted minimal access procedures. Eur J Surg Oncol. 2009;35(3):281-288.

28. Song J, Kang WH, Oh SJ, Hyung WJ, Choi SH, Noh SH. Role of robotic gastrectomy using da Vinci system compared with laparoscopic gastrectomy: initial experience of 20 consecutive cases. Surg Endosc. 2009;23(6):1204-1211.

29. Kang BH, Xuan Y, Hur H, Ahn CW, Cho YK, Han SU. Comparison of surgical outcomes between robotic and laparoscopic gastrectomy for gastric cancer: the learning curve of robotic surgery. J Gastric Cancer. 2012;12(3):156-163.

30. Zhou J, Shi Y, Qian F, et al. Cumulative summation analysis of learning curve for robot-assisted gastrectomy in gastric cancer. J Surg Oncol. 2015;111(6):760-767.

31. Lee JH, Ryu KW, Lee JH, et al. Learning curve for total gastrectomy with D2 lymph node dissection: cumulative sum analysis for qualified surgery. Ann Surg Oncol. 2006;13(9):1175-1181.

32. Zhang $X$, Tanigawa $N$. Learning curve of laparoscopic surgery for gastric cancer, a laparoscopic distal gastrectomy-based analysis. Surg Endosc. 2009;23(6):1259-1264.

33. Jung DH, Son SY, Park YS, et al. The learning curve associated with laparoscopic total gastrectomy. Gastric Cancer. 2016;19(1):264-272.

34. Shen WS, Xi HQ, Chen L, Wei B. A meta-analysis of robotic versus laparoscopic gastrectomy for gastric cancer. Surg Endosc. 2014;28(10):2795-2802.

35. Xiong B, Ma L, Zhang C. Robotic versus laparoscopic gastrectomy for gastric cancer: a meta-analysis of short outcomes. Surg Oncol. 2012;21(4):274-280.

36. Lee JH, Park DJ, Kim HH, Lee HJ, Yang HK. Comparison of complications after laparoscopy-assisted distal gastrectomy and open distal gastrectomy for gastric cancer using the Clavien-Dindo classification. Surg Endosc. 2012;26(5):1287-1295.
37. Lee KG, Lee HJ, Yang JY, et al. Risk factors associated with complication following gastrectomy for gastric cancer: retrospective analysis of prospectively collected data based on the Clavien-Dindo system. J Gastrointest Surg. 2014;18(7):1269-1277.

38. Kim DJ, Lee JH, Kim W. Comparison of the major postoperative complications between laparoscopic distal and total gastrectomies for gastric cancer using Clavien-Dindo classification. Surg Endosc. 2015;29(11):3196-3204.

39. Liang YX, Guo HH, Deng JY, et al. Impact of intraoperative blood loss on survival after curative resection for gastric cancer. World J Gastroenterol. 2013;19(33):5542-5550.

40. Mizuno A, Kanda M, Kobayashi D, et al. Adverse effects of intraoperative blood loss on long-term outcomes after curative gastrectomy of patients with Stage II/III gastric cancer. Dig Surg. 2016;33(2): 121-128.

41. Kamei T, Kitayama J, Yamashita H, Nagawa H. Intraoperative blood loss is a critical risk factor for peritoneal recurrence after curative resection of advanced gastric cancer. World J Surg. 2009;33(6):1240-1246.

42. Caruso S, Patriti A, Roviello F, G et al. Robot-assisted laparoscopic vs open gastrectomy for gastric cancer: systematic review and metaanalysis. World J Clin Oncol. 2017;8(3):273-284.

43. Obama K, Kim YM, Kang DR, et al. Long-term oncologic outcomes of robotic gastrectomy for gastric cancer compared with laparoscopic gastrectomy. Gastric Cancer. Epub 2017 Jun 21.

44. Silverstein A, Costas-Chavarri A, Gakwaya MR, et al. Laparoscopic versus open cholecystectomy: a cost-effectiveness analysis at Rwanda Military Hospital. World J Surg. 2017;41(5):1225-1233.

45. Gerber MH, Delitto D, Crippen CJ, et al. Analysis of the cost effectiveness of laparoscopic pancreatoduodenectomy. J Gastrointest Surg. 2017;21(9):1404-1410.

46. Lee SS, Chung HY, Kwon OK, Yu W. Long-term quality of life after distal subtotal and total gastrectomy: symptom-and behavior-oriented consequences. Ann Surg. 2016;263(4):738-744.

47. Bottomley A. The cancer patient and quality of life. Oncologist. 2002;7(2):120-125.
Cancer Management and Research

\section{Publish your work in this journal}

Cancer Management and Research is an international, peer-reviewed open access journal focusing on cancer research and the optimal use of preventative and integrated treatment interventions to achieve improved outcomes, enhanced survival and quality of life for the cancer patient. The manuscript management system is completely online and includes

\section{Dovepress}

a very quick and fair peer-review system, which is all easy to use. Visit http://www.dovepress.com/testimonials.php to read real quotes from published authors. 